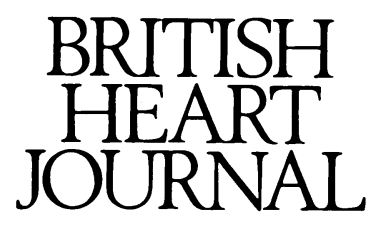

\title{
Editorial
}

\section{Ambulatory ST segment monitoring after myocardial infarction}

The significance of transient myocardial ischaemia in patients with chronic angina, is now reasonably well established, and ambulatory ST segment monitoring probably adds little to the information available from exercise stress testing. There is much less information available on transient ischaemia in acute coronary syndromes but recent work suggests that ambulatory monitoring may have prognostic significance in patients with unstable angina. ${ }^{1-5}$

\section{Prevalence and characteristics of transient myo- cardial ischaemia after myocardial infarction}

Transient myocardial ischaemia seems to be less common in survivors of myocardial infarction than in other subgroups with coronary artery disease. Ischaemic episodes were detected in $14-34 \%$ of patients in studies using only one 24 hour recording period..$^{6-13}$ There are several explanations for this relatively low prevalence of transient ischaemia. Firstly, shortly after infarction patients generally have a low activity level and thus a reduction in myocardial oxygen demand. Secondly, in the early post-infarction period unresolved baseline ST segment deviation may mask further significant ST segment depression, and later the presence of abnormal $Q$ waves makes it increasingly difficult to distinguish ischaemic episodes. ${ }^{14}$ Thirdly, an association between left ventricular dysfunction and a low prevalence of transient ST segment depression has recently been reported. ${ }^{15}$ This observation accords with the detection of more transient ischaemia after non- $Q$ wave than after $Q$ wave infarction..$^{714}$ In the early in-hospital post-infarction period transient ischaemia may be related more to supply than to demand, unlike the pathophysiological mechanism later on. ${ }^{10}$

Eighty one per cent to $100 \%$ of ischaemic episodes seem to be symptomless. ${ }^{8911-131617}$ Thus a greater proportion of ischaemic episodes are silent in patients early after myocardial infarction than in other subgroups with coronary artery disease. In patients who are able to perform predischarge exercise stress testing, ambulatory monitoring is considerably less sensitive in detecting patients with ST segment depression. ${ }^{818}$ These results suggest that ambulatory ST segment monitoring should not be used as a routine screening test for continuing ischaemia in the early post-infarction period. Ambulatory monitoring, however, seems to identify patients with a poor exercise test result. This is apparent both in terms of more severe ischaemic electrocardiographic changes and a reduced haemodynamic response during postinfarction stress testing. ${ }^{11} 18$
Prognostic significance of transient myocardial ischaemia after myocardial infarction

Transient myocardial ischaemia detected within one week after hospital admission seems to be predictive of early recurrent cardiac events. The available evidence, however, is limited by small numbers of patients and the choice of soft clinical end points. ${ }^{6} 1617$

In another series of prognostic studies ambulatory monitoring was performed 1-3 weeks after myocardial infarction. $^{7-91418}$ At this time many recurrent events already have occurred, a fact that will always affect the prognostic value of transient ischaemia. The available data suggest that ambulatory ST segment monitoring can be used to identify those survivors of myocardial infarction who are at an increased risk of recurrent cardiac events during 1-2.5 years of follow up. The severity of key end points in different studies ranges from mortality $^{78}$ through combined hard events ${ }^{9}$ mainly to angina pectoris. ${ }^{1418}$ This difference probably indicates that most studies were of too few patients and that there was a considerable variation in terms of patient selection between studies. The relative value of ambulatory ST segment monitoring in the low risk group of patients who are able to perform a predischarge exercise stress test remains unclear. ${ }^{81418}$

One common finding in the post-infarction studies is the poor association between transient myocardial ischaemia and recurrent non-fatal infarction. This may be explained in part by the fact that myocardial infarction can often result from acute plaque rupture of what were only mild coronary artery lesions. Thus in $48-66 \%$ of patients with mild to moderate coronary artery disease myocardial infarction was shown to occur because of the occlusion of a coronary artery that did not contain an obstructive $(<50 \%)$ stenosis on an earlier coronary angiogram. ${ }^{19} 20$ Coronary artery lesions of this severity are generally not flow limiting and will probably not result in myocardial ischaemia - silent or symptomatic-during ordinary daily living. It should be emphasised that the applicability of the data on post-infarction ambulatory monitoring is limited because most of the studies either predate the thrombolytic era or include only a small proportion of patients who have received reperfusion therapy.

\section{Summary and conclusions}

The prevalence of transient myocardial ischaemia after myocardial infarction seems to be lower than in other subgroups with coronary artery disease. In postinfarction patients, however, a greater proportion of 
ischaemic episodes are silent. At present there is substantial evidence that transient ischaemia provides prognostic information in different subsets of patients with previous myocardial infarction, but there is considerable disagreement about how this is expressed in terms of cardiac events. Small patient numbers, patient selection, and different timing of ambulatory monitoring are proposed as important reasons for the inconsistent findings.

The precise role of ambulatory ST segment monitoring in clinical practice has yet to be established. Direct comparisons with exercise stress testing may not be appropriate for two reasons. Firstly, the main advantage of ambulatory monitoring may be that it can be performed early after infarction at the time of maximum risk. Secondly, it can be performed in most patients after infarction, including those recognised as being at high risk who are unable to perform an exercise stress test.

Department of Cardiology,

HANS MICKLEY Odense University Hospital,

5000 Odense C, Denmark

1 Gottlieb SO, Weisfeldt ML, Ouyang P, Mellits D, Gerstenblith G. Silent ischemia as a marker for early unfavourable outcomes in patients with unstable angina. N Engl ₹ Med 1986;314:1214-9.

2 Gottlieb SO, Weisfeldt ML, Ouyang P, Mellits D, Gerstenblith G. Silent ischemia predicts infarction and death during 2 year follow-up of unstable angina. F Am Coll Cardiol 1987;10:756-60.

3 Nademanee K, Intarachot V, Josephson MA, Rieders D, Mody FV, Singh BN. Prognostic significance of silent myocardial ischemia in patients with unstable angina. $\mathcal{F} \mathrm{Am}$ Coll Cardiol 1987;10:1-9.

4 Romeo F, Rosano GMC, Martuscelli E, Valente A, Reale A. Unstable angina: role of silent ischemia and total ischemic time (silent plus painful ischemia), a 6-year follow-up. $f \mathrm{Am}$ Coll Cardiol 1992;19: $1173-9$.

5 Wilcox I, Freedman SB, Kelly DT, Harris PJ. Clinical significance of silent ischemia in unstable angina pectoris. Am $\mathcal{F}$ Cardiol 1990;65:
1313-6.

6 Cheng A, Shanit D, Greenbaum R. ST-segment depression in the early post-infarct period-a predictor of increased incidence of cardiac complications [abstr]. Eur Heart f 1992;13:446.

7 Gottlieb SO, Gottlieb SH, Achuff SC, et al. Silent ischemia on Holter monitoring predicts mortality in high-risk postinfarction patients. FAMA 1988;259:1030-5.

8 Bonaduce D, Petretta M, Lanzillo T, et al. Prevalence and prognostic significance of silent myocardial ischaemia detected by exercise test and continuous ECG monitoring after acute myocardial infarction. Eur Heart f 1991;12:186-93.

9 Petretta M, Bonaduce D, Bianchi V, et al. Characterization and prognostic significance of silent myocardial ischemia on predischarge electrocardiographic monitoring in unselected patients with myocardial infarction. Am $\mathcal{F}$ Cardiol 1992;69:579-83.

10 Currie P. Saltissi S. Transient myocardial ischaemia after acute myocardial infarction. Br Heart $\mathcal{f} 1990 ; 64: 299-303$.

11 Currie P, Saltissi S. Transient ischaemia after acute myocardial infarction: relationship to exercise ischaemia. Eur Heart $\mathcal{f} 1991 ; 12: 395-400$.

12 Mickley $H$, Pless $P$, Nielsen JR, Møller M. Circadian variation of transient myocardial ischemia in the early out-of-hospital period after transient myocardial ischemia in the early out-of-hospital period
first acute myocardial infarction. $A m \mathcal{F}$ Cardiol 1991;67:927-32.

13 Nürnberg $M$, Biber B, Buchelt $M$, Steinbach $K$. Stumme Ischämie im Langzeit-EKG der Frühen Postinfarktperiode. Wien Klin Wochenschr Langzeit-EKG

14 Mickley $H$, Pless $P$, Nielsen JR, Møller M. Residual myocardial ischaemia in first non- $Q$ versus $Q$ wave infarction: maximal exercise testing and ambulatory ST-segment monitoring. Eur Heart f 1993;14:18-25.

15 Quyyumi AA, Panza JA, Diodati JG, Dilsizian V, Callahan TS, Bonow RO. Relation between left ventricular function at rest and with exercise and silent myocardial ischemia. 7 Am Coll Cardiol 1992;19:962-7.

16 Ouyang $P$, Chandra NC, Gottlieb SO. Frequency and importance of silent myocardial ischemia identified with ambulatory electrocardiographic monitoring in the early in-hospital period after acute myocardia infarction. Am $\mathcal{F}$ Cardiol 1990;65:267-70.

17 Langer A, Minkowitz J, Dorian P, et al. Pathophysiology and prognostic significance of Holter-detected ST segment depression after myocardial infarction. $\mathcal{F} \mathrm{Am}$ Coll Cardiol 1992;20:1313-7.

18 Mickley H, Pless P, Nielsen JR, Berning J, Møller M. Transient myocardial ischemia after a first acute myocardial infarction and its relation to clinical characteristics, predischarge exercise testing and cardiac to clinical characteristics, predischarge exercise testing
events at one-year follow-up. Am $\mathcal{F}$ Cardiol 1993;71:139-44.

19 Ambrose JA, Tannenbaum MA, Alexopoulos D, et al. Angiographic progression of coronary artery disease and the development of myocardial gression of coronary artery disease and the
infarction. $\mathcal{F} \mathrm{Am}$ Coll Cardiol 1988;12:56-62.

20 Little WC, Constantinescu M, Applegate RJ, et al. Can coronary angiography predict the site of a subsequent myocardial infarction in patients with mild-to-moderate coronary artery disease? Circulation 1988;78: $1157-66$. 